\title{
Review
}

\section{Paediatric pressure injuries: considerations for this patient cohort}

Boylan C

Keywords premature neonate, neonate, medical devices, nutrition

For referencing Boylan C. Paediatric pressure injuries: considerations for this patient cohort. Wound Practice and Research 2020; 28(2):84-89.

DOI https://doi.org/10.33235/wpr.28.2.84-89

\section{Abstract}

Paediatric patients are at risk of developing pressure injuries; however, there is a paucity of literature addressing the specific considerations related to pressure injury prevention for this patient cohort. Pressure injuries are generally linked to the adult patient population, hence most of the literature available to date is related to prevention and management of pressure injuries in older people or adult patients considered to be at high risk. The aim of this paper is to outline recommended pressure injury risk assessments for the neonatal/paediatric patient and to highlight some specific pressure injury prevention considerations when caring for this often-overlooked patient population.

\section{Background}

Hospitalised children and neonates are recognised as a specific population that is at higher risk of pressure injuries. Paediatric pressure injury prevalence rates of $0.47 \%{ }^{1}$ to $75 \%{ }^{2}$ have been reported in the literature. Reported pressure injury prevalence ranges according to the methodologies used across studies, for example type of data collection, population inclusion criteria etc; however, the highest prevalence rates were reported in children and neonates with chronic illness, in critical care units, and with medical devices ${ }^{3,4}$.

The 2019 European Pressure Ulcer Advisory Panel (EPUAP), National Pressure Injury Advisory Panel (NPIAP) and Pan Pacific Pressure Injury Alliance (PPPIA) Prevention and treatment of pressure ulcers/injuries: clinical practice guideline (the International guideline) recognises the special needs of children and neonates. The International guideline includes

\section{Carmel Boylan}

RN, BN, STN, MN (Nurse Practitioner)

Stomal/Wound Nurse Practitioner, Perth Children's

Hospital, Perth, WA

Email carmel.boylan@health.wa.gov.au recommendations and best practice statements that address specific considerations for the neonatal and paediatric population in all clinical settings. Recommendations and best practice statements from the International guideline that are specific to addressing pressure injury prevention for paediatric patients and neonates are discussed throughout this paper. For each recommendation, the International guideline outlines strength of evidence and strength of recommendation based on the quantity, level and consistency of the evidence ${ }^{5}$. An explanation of the evidence ranking systems is provided in Table 1 and Table 2.

\section{Neonatal and paediatric pressure injury risk factors}

Paediatric patients and neonates have many of the risk factors for pressure injury that applies to an adult patient, as well as some additional specific considerations. These additional risk factors include skin maturity, perfusion and oxygenation status and presence of a medical device (all ranked as strength of evidence $=\mathrm{B} 1$; strength of recommendation $=\uparrow \uparrow)^{5}$, and severity of illness and the length of stay in critical care units (both ranked as strength of evidence=B1; strength of recommendation $=\uparrow)^{5}$. In addition, anatomical factors influence a different profile for location of paediatric pressure injuries. The neonate and younger child have a larger head size in proportion to the rest of the body, placing them at higher risk for occipital pressure injuries which are seen less often in adults ${ }^{3,6}$.

The stratum corneum does not function as well in the first year of life and the infant skin is 30\% thinner than that of an adult ${ }^{7}$. In the neonate the developmental stage of the skin correlates to the gestational age. This can vary from almost no stratum corneum (23-24 weeks' gestation) to $30 \%$ (25-30 weeks' gestation). ${ }^{7}$ The dermis is thin, with shorter collagen and elastin fibres. Additionally, the bond between the epidermal and dermal layer is weak and can easily be separated, for example with forces from movement or when medical devices or topical adhesive devices are being removed ${ }^{7}$. The consequence of this immature skin places the 
Table 1. Strength of evidence ranking ${ }^{5}$. (Reprinted with permission from EPUAP/NPIAP/PPPIA).

\begin{tabular}{|l|l|}
\hline A & $\begin{array}{l}\text { - More than one high quality Level } 1 \text { study providing direct evidence } \\
\text { - Consistent body of evidence }\end{array}$ \\
\hline B & $\begin{array}{l}\text { - Level } 1 \text { studies of moderate or low quality providing direct evidence } \\
\text { - Level } 2 \text { studies of high or moderate quality providing direct evidence } \\
\text { - Most studies have consistent outcomes and inconsistencies can be explained }\end{array}$ \\
\hline B2 & $\begin{array}{l}\text { - Level } 2 \text { studies of low quality providing direct evidence } \\
\text { - Level } 3 \text { or } 4 \text { studies (regardless of quality) providing direct evidence } \\
\text { - Most studies have consistent outcomes and inconsistencies can be explained }\end{array}$ \\
\hline C & $\begin{array}{l}\text { - Level } 5 \text { studies (indirect evidence), for example studies in normal human subjects, humans with } \\
\text { other types of chronic wounds, animal models }\end{array}$ \\
\hline $\begin{array}{l}\text { Good practice } \\
\text { statement (GPS) }\end{array}$ & $\begin{array}{l}\text { - Surrounding the topic } \\
\text { Guideline Governance Group to be significant for clinical practice }\end{array}$ \\
\hline
\end{tabular}

infant at higher risk for skin damage associated with pressure and shear ${ }^{4,8,9,10}$, as demonstrated in a prognostic study that found immature skin was associated with approximately a $650 \%$ increase in risk of a pressure injury (odds ratio $[\mathrm{OR}]=7.6$ (95\% confidence interval $[\mathrm{Cl}] 1.58-36.71, \mathrm{p}=0.012)^{4}$.

Medical devices are routinely used to deliver daily treatment to children in hospital. Studies have reported that medical devices are the leading cause of pressure injuries in this patient population, especially in critical care units ${ }^{9}$. These devices include lifesaving equipment such as a ventilator in the intensive care setting, respiratory support devices (for example continuous positive airway pressure [CPAP] and oxygen delivery tubing/masks), nasogastric feeding tubes, intravenous access devices, urinary catheters, braces, cervical collars and various orthotics. In the intensive care setting, children will often have multiple medical devices attached to deliver lifesaving treatments. Fujii et al. (2010) ${ }^{4}$ report $86 \%$ of pressure injuries found while conducting a prospective cohort study over seven neonatal intensive care units were related to CPAP or nasal direction positive airway pressure (DPAP), while Schluer et al. (2012) ${ }^{10}$ reports a prevalence rate of $40 \%$ for medical device-related pressure injuries (MDRPI) in one paediatric healthcare facility. Prognostic studies have shown that endotracheal intubation ${ }^{4}$, CPAP $^{11}$, mechanical ventilation ${ }^{11}$, high frequency oscillatory ventilation ${ }^{11}$ and extracorporeal membrane oxygenation devices ${ }^{11}$ are all associated with a statistically significantly increase in MDRPI risk for both children and neonates in intensive care. Use of many of these medical devices is also indicative of alteration in the child's perfusion and oxygenation status, which is in itself a risk factor for pressure injuries ${ }^{5}$ and must be addressed in the patient screening and observation protocol ${ }^{11}$.

A child that requires hospitalisation in an intensive care setting or who has multiple complex medical problems will often have an extended hospitalisation which further increases the risk of pressure injury development ${ }^{11}$. Severity of illness is shown to increase risk of pressure injuries by more than double $(\mathrm{OR}=1.132,95 \% \mathrm{Cl} 1.055-1.215, \mathrm{p}<0.05)$ and a hospital stay of more than 4 days is related to almost a $500 \%$ increase in risk $(\mathrm{OR}=5.68,95 \% \mathrm{Cl} 4.481-7.21$, $\mathrm{p}<0.001)^{11}$.

Nutritional status can also impact on pressure injury development and healing ${ }^{5}$, particularly in neonates and children who have a high nutritional requirement to meet their growing bodily needs ${ }^{12}$. Added to this, patients in an intensive care setting may either not be allowed or be unable to tolerate diet; this compromises their nutrition and consequently increases their risk for pressure injury. For children who have comorbidities as well as a pressure injury, the nutritional demand required to enhance wound healing is therefore compromised ${ }^{12,13}$.

\section{Assessing paediatric patients: risk, nutrition and pain}

Children go through a number of developmental stages that impacts their ability to communicate effectively. Until a child has acquired language skills a clinician is reliant on nonverbal cues to identify when the child is in pain or feeling

Table 2. Strength of recommendation ranking ${ }^{5}$. (Reprinted with permission from EPUAP/NPIAP/PPPIA).

\begin{tabular}{|l|l|}
\hline$\uparrow \uparrow$ & Strong positive recommendation: definitely do it \\
\hline$\uparrow$ & Weak negative recommendation: probably do it \\
\hline$\leftrightarrow$ & No specific recommendation \\
\hline$\downarrow$ & Weak positive recommendation: probably do it \\
\hline$\downarrow \downarrow$ & $\begin{array}{l}\text { Strong negative recommendation: definitely don't } \\
\text { do it }\end{array}$ \\
\hline
\end{tabular}


unwell. Children who have an intellectual disability will also often have difficulty communicating their needs in a clear manner. Clinicians often rely on the parent or carer to assist in understanding the child's body language or identifying what the child is trying to communicate. Engaging parents and other informal caregivers in assessment is therefore a core component of the gold standard care model for paediatric and neonatal intensive care units - family-centred care ${ }^{14}$. The parent or carer is a valuable source of information specific to their child. When conducting the patient assessment, the clinician should involve the parent to elicit important factors regarding the individual characteristics of their child.

A pressure injury risk screening should be conducted as soon as possible after admission to a healthcare facility. To screen for pressure injury risk, a structured approach is taken to rapidly identify a child who is likely to be at pressure injury risk. For most hospitalised children and neonates, presence of the population-specific risk factors discussed above will indicate that the child requires a full and comprehensive pressure injury risk assessment. When undertaking the risk assessment, a structured approach should be undertaken that incorporates general and population-specific risk factors. A paediatric-specific risk assessment tool can also be used. In Australia, the most commonly used tools are the Glamorgan paediatric pressure injury risk assessment scale ${ }^{15,16}$ and the Braden Q. Both were developed based on literature reviews of risk factors in adults. While the Braden $Q$ is primarily derived from the adult Braden scale ${ }^{17}$, the Glamorgan tool is also based on data collection from paediatric nurses and assessments conducted in children from hospitals across the UK, followed by reliability testing conducted in critically ill children and neonates ${ }^{15}$.
Comparisons between the Glamorgan scale and the Braden $Q$ have demonstrated that the tools have similar validity when assessing both neonates in the intensive care and critically ill children ${ }^{17}$; however, a meta-analysis has suggested low predictive validity when applying Braden $Q$ to children and babies in critical care settings ${ }^{18}$. While being aware that there are limitations to all risk assessment tools ${ }^{18}$, both the Glamorgan scale and the Braden Q can provide a reliable assessment of the child's pressure injury risk when used in conjunction with clinical judgement ${ }^{5}$.

The International guideline ${ }^{5}$ recommendation 1.10 states "Consider the impact of impaired nutritional status on the risk of pressure injuries" (strength of evidence $=\mathrm{C}$; strength of recommendation $=\uparrow$ ). Although the evidence for nutritional status as a risk factor is from adult populations, the guideline recommends nutritional screening and assessment for all children admitted to hospital ${ }^{5}$ due to the increased nutritional needs children have in general, which are compounded during critical illness ${ }^{13}$. Nutritional screening and assessment should be age appropriate, and assessment should be repeated regularly throughout the hospital admission (at least weekly) ${ }^{5,19}$. Paediatric patients admitted to the intensive care setting should have a comprehensive nutritional assessment conducted within 48 hours of admission. There are several paediatric nutrition screening and assessment tools, tested in a range of different paediatric populations, as reported in Table 3. Guidance and support in the choice of tool from the dietetic department in the healthcare facility is also suggested.

A thorough skin assessment should be conducted as a part of every risk assessment, and at least once per shift or more frequently for patients in a critical care unit. As with adults,

Table 3. Paediatric nutrition screening and assessment tools (adapted from the International guideline ${ }^{5}$ and used with permission)

\begin{tabular}{|c|c|c|c|}
\hline $\begin{array}{l}\text { Paediatric and neonate } \\
\text { nutrition screening tool }\end{array}$ & $\begin{array}{l}\text { Evidence for } \\
\text { identifying } \\
\text { pressure injury } \\
\text { risk status }\end{array}$ & $\begin{array}{l}\text { Screening (S) / } \\
\text { assessment (A) } \\
\text { tool }\end{array}$ & $\begin{array}{l}\text { Clinical setting and population in which tool is } \\
\text { tested }\end{array}$ \\
\hline $\begin{array}{l}\text { Subjective global nutritional } \\
\text { assessment for children (SGNA) }\end{array}$ & No & $S, A$ & $\begin{array}{l}\text { - Hospitalised children aged } 1 \text { month to } 18 \text { years }^{20} \\
\text { - Children with cerebral palsy aged } 1-12 \text { years }{ }^{21}\end{array}$ \\
\hline $\begin{array}{l}\text { Paediatric nutrition screening } \\
\text { tool (PNST) }\end{array}$ & No & $S, A$ & $\begin{array}{l}\text { - Hospitalised neonates and children aged birth to } \\
16 \text { years }^{22}\end{array}$ \\
\hline $\begin{array}{l}\text { Screening tool for the } \\
\text { assessment of malnutrition in } \\
\text { paediatrics (STAMP) }\end{array}$ & No & S, A & $\begin{array}{l}\text { - Hospitalised neonates and children aged 2-7 } \\
\text { years }{ }^{23} \\
\text { - Children with spinal cord injury }{ }^{24}\end{array}$ \\
\hline $\begin{array}{l}\text { Paediatric Yorkhill malnutrition } \\
\text { score (PYMS) }\end{array}$ & No & S & - Hospitalised children aged 1-16 years ${ }^{25}$ \\
\hline $\begin{array}{l}\text { Screening tool for the risk of } \\
\text { impaired nutritional status and } \\
\text { growth (STRONGkids) }\end{array}$ & No & S & $\begin{array}{l}\text { - Hospitalised children from birth to } 17 \text { years }{ }^{26} \\
\text { - Hospitalised children aged } \geq 1 \text { year and not in } \\
\text { critical care }{ }^{27}\end{array}$ \\
\hline
\end{tabular}


Table 4. Selection of pain assessment tools appropriate for assessing pressure injury pain (adapted from the International guideline ${ }^{5}$ and used with permission)

\begin{tabular}{|l|l|l|l|}
\hline $\begin{array}{l}\text { Paediatric and neonate pain } \\
\text { assessment tool }\end{array}$ & $\begin{array}{l}\text { Evidence for } \\
\text { identifying pressure } \\
\text { injury pain }\end{array}$ & $\begin{array}{l}\text { Evidence for } \\
\text { identifying other } \\
\text { types of pain }\end{array}$ & $\begin{array}{l}\text { Clinical Setting in which } \\
\text { Tool is Tested }\end{array}$ \\
\hline $\begin{array}{l}\text { FLACC (face; leg; activity; cry; } \\
\text { consolability) }\end{array}$ & No & Yes & $\begin{array}{l}\text { Children } 2 \text { months to } 7 \text { years of age } \\
\text { with postoperative pain }{ }^{32}\end{array}$ \\
\hline $\begin{array}{l}\text { CRIES (crying; requires } \mathrm{O}_{2} \text { for } \\
\text { saturation }>95 \% ; \text { increasing vital } \\
\text { signs; expression; sleepless) scale }\end{array}$ & No & Yes & Neonates up to 6 months $^{33,34}$ \\
\hline
\end{tabular}

a head-to-toe assessment, paying specific attention to bony prominences, provides a structured approach. For neonates and smaller children, particular attention should be paid to assessing the occiput. The hair may need to be trimmed (with parental permission) for close inspection when the risk is higher (for example, children wearing cervical collars). For all paediatric patients and neonates, the skin assessment includes examination under and around medical devices and their securements, where it is safe to do $\mathrm{so}^{28}$.

Pain related to pressure injury can sometimes be underreported. However, patients who have pressure injuries have reported pain related specifically to the pressure injury wounds ${ }^{29}$. A child with a painful pressure injury may be left a legacy of painful memories and a fear of future hospital admission. The level of pain reported will differ according to the severity of the wound, and can often be one of the most distressing symptoms the patient experiences ${ }^{30,31}$. The 2019 International guideline recommends conducting a pain assessment on all individuals using a recognised pain assessment tool suited to the patient circumstance. For the neonate and up to 6 months of age the recommended tool is the CRIES (crying; requires $\mathrm{O}_{2}$ for saturation $>95 \%$; increasing vital signs; expression; sleepless) scale ${ }^{5}$. The recommended pain assessment tool for children 2 months to 7 ears of age is FLACC (face; leg; activity; cry; consolability) ${ }^{5}$ (Table 4). When assessing pain in neonatal and paediatric patients it is essential to recognise non-verbal cues and the patient's body language ${ }^{5}$ as well as the parents' insight into their child's behaviour.

\section{Interventions for preventing pressure injuries in neonates and children}

Good communication between all members of the healthcare team is required to negotiate a coordinated approach to treatment for neonatal and paediatric patients. An important consideration when nursing paediatric patients is involvement of the parent/carer as a member of the healthcare team who gives input into all decisions. The parent/carer can often be apprehensive about speaking up or may be scared to even touch their child especially in an intensive care setting. However, when provided with appropriate support and direction, parents can assist in the care of their child in pressure injury prevention. They can be provided with education on what a pressure injury is, what to watch for when inspecting their child's skin, how to gently reposition a limb or body part to alleviate pressure, and how to speak up if they observe their child to be in discomfort. As a healthcare professional, clinical judgement is extremely valuable and should not be discounted when a concern for patient wellbeing is a concern.

Clustering of care for the premature neonate or critically ill child is important in order to reduce unnecessary disruption to the patient, potential stress, and the frequency and length of time to provide interventions ${ }^{35}$. For example, conduct a skin assessment, reposition and rotate medical devices and manage incontinence at the same time as taking critical observations.

Support surfaces should be chosen that are appropriate for the weight of the patient. This is particularly important when choosing alternating air mattresses for paediatric patients. When an alternating air mattress is the support surface of choice, a replacement mattress is more appropriate than an overlay as this does not raise the mattress level so high as to pose a risk for the child or baby falling out of bed. High specification foam mattresses have been shown to reduce the interface pressure to the occiput in premature neonates ${ }^{5}$.

As with adults, children and neonates at risk of pressure injuries require frequent repositioning on a schedule that meets the individual's needs based on skin response and risk level. Fully repositioning the critically ill paediatric patient may not always be possible; however, the 2019 International guideline ${ }^{5}$ recommends using slow gradual turns (Good practice statement [GPS]) and frequent small shifts in body position (strength of evidence $=\mathrm{B} 1$; strength of recommendation $=\uparrow$ ). Special attention should be given to repositioning the child/baby's head; even small degree changes during side-side will reduce direct pressure on the occiput.

Reducing the risk of MDRPI and their securements is a specific concern for children. Recommendation 8.4 of the International guideline 2019 suggests medical devices be regularly rotated or repositioned, support be placed for 
medical devices to minimise pressure and shear and, where possible, to remove the medical device as soon as it is medically possible ${ }^{5}$ (GPS). Medical devices designed for oxygen delivery are particularly associated with a higher risk of MDRPI ${ }^{11}$. The 2019 International guideline recommends that, where possible, alternating between a well-fitted oxygen mask and nasal prongs can reduce MDRPIs in neonates (strength of evidence $=\mathrm{B} 1$; strength of recommendation $=\uparrow$ ) and older children (GPS). The guideline also recommends the placement of prophylactic dressings under medical devices to reduce pressure and skin injury ${ }^{5}$ (strength of evidence=B1; strength of recommendation $=\uparrow$ ). Hospitalised children or infants often require adhesive tapes that are fastened tightly to the skin to secure medical devices. This can result in pressure directly over bony prominences or delicate structures. Consideration to the use of an interface under the tape can disperse this pressure and help prevent skin injury.

Neonatal and paediatric patients identified as nutritionally deficient should have a nutritional supplementation plan specific to their individual nutritional requirements. This plan requires the expertise of a paediatrician, paediatric dietician or other suitably qualified healthcare professional to provide direction in regard to nutritional support requirement and nutritional supplementation that will meet the child's growth needs as well as any nutritional deficits and nutritional needs during critical illness ${ }^{36}$. There is a lack of research on the most effective nutrition regimens for preventing pressure injuries in children and neonates; however, the International guideline ${ }^{5}$ suggests consideration be given to fortified foods and ageappropriate nutritional supplements (GPS), preferencing enteral feeding options when possible.

\section{Conclusion}

Neonates and paediatric patients are vulnerable patient cohorts that have specific risk factors for the development of pressure injuries. These factors include skin immaturity and fragility, critical illness requiring hospitalisation in a critical care unit, long hospital admission and the use of multiple medical devices. Undertaking a comprehensive assessment of the child, including pressure injury risk, skin assessment, nutritional status and pain, are paramount to understanding paediatric patients' needs and implementing an individualised pressure injury prevention and management plan.

Patient comfort and compliance is paramount to successfully implementing pressure injury prevention strategies. This requires good communication between the clinician, patient and the child's parent/carer.

\section{Acknowledgements}

A/Prof Emily Haesler for her support and mentorship in preparing this paper.

\section{Conflict of interest}

The authors declare no conflicts of interest.

\section{Funding}

The authors received no funding for this study.

\section{References}

1. Baldwin KM. Incidence and prevalence of pressure ulcers in children. Adv Skin Wound Care 2002;15(3):121-4.

2. Samaniego IA. A sore spot in pediatrics: risk factors for pressure ulcers. Pediatr Nurs 2003 Jul;29(4):278-82.

3. Habiballah $L$, Tubaishat $A$. The prevalence of pressure ulcers in the paediatric population. J Tissue Viability 2016;25(2):127-134.

4. Fujii K, Sugama J, Okuwa M, Sanada H, Mizokami Y. Incidence and risk factors of pressure ulcers in seven neonatal intensive care units in Japan: a multisite prospective cohort study. Int Wound J 2010;7(5):323-328.

5. European Pressure Ulcer Advisory Panel (EPUAP), National Pressure Injury Advisory Panel (NPIAP), Pan Pacific Pressure Injury Alliance (PPPIA). Prevention and treatment of pressure ulcers/injuries: clinical practice guidelines. The international guideline. 3rd ed. Emily Haesler, editor. EPUAP, NPIAP, PPPIA; 2019.

6. Razmus I, Lewis L, Wilson D. Pressure ulcer development in infants: state of the science. J Health Qual 2008;30(5):36-42.

7. Stamatas GN, Nikolovski J, Mack M, et al. Infant skin physiology and development during the first years of life: a review of recent findings based on in vivo studies. Int $\mathrm{J}$ Cosmetic Sci 2011;33(1):17-21.

8. Su Y,Nan G. Manipulation and bracing for the treatment of congenital clubfoot in newborns and infants. BMC Musculoskelet Disord 2014;15:363.

9. Baharestani MM, Ratcliff CR. Pressure ulcers in neonates and children: an NPUAP white paper. Adv Skin Wound Care 2007;20(4):208-20.

10. Schluer AB, Halfens RJ, Schols JGA. Pediatric pressure ulcer prevalence: a multicenter, cross-sectional, point prevalence study in Switzerland. Ostomy Wound Manage 2012;58(7):18-31.

11. Schindler CA, Mikhailov TA, Kuhn EM, et al. Protecting fragile skin: nursing interventions to decrease development of pressure ulcers in pediatric intensive care. Am J Crit Care 2011;20(1):2635.

12. Mehta N, Compher C, ASPEN Board of Directors. A.S.P.E.N. Clinical guidelines: nutrition support of the critically ill child. J Parenter Enteral Nutr 2009;33(3):260-276.

13. Tume LN, Valla FV, Joosten K, et al. Nutritional support for children during critical illness: European Society of Pediatric and Neonatal Intensive Care (ESPNIC) metabolism, endocrine and nutrition section position statement and clinical recommendations. Intensive Care Med 2020;46(3):411-425. doi:10.1007/s00134-019-05922-5

14. Shields L, Zhou H, Pratt J, Taylor M, Hunter J, Pascoe E. Familycentred care for hospitalised children aged $0-12$ years. Cochrane Database System Rev 2012; Issue 10. Art. No: CD004811. doi:10.1002/14651858.CD004811.pub3

15. Willock J, Anthony D, Richardson J. Inter-rater reliability of Glamorgan paediatric pressure ulcer risk assessment scale. Paediatr Nurs 2008;20(7):14-19.

16. Willock, J. Interrater reliability of the Glamorgan scale: overt and covert data. Br J Nurs 2013;22(20):S4-S9.

17. Willock J, Habiballah L, Long D, Palmer K, Anthony D. A comparison of the performance of the Braden $Q$ and the Glamorgan paediatric pressure ulcer risk assessment scales in general and intensive care paediatric and neonatal units. J Tissue Viability 2016;25(2):119-126. 
18. Liao Y, Gao G, Mo L. Predictive accuracy of the Braden Q scale in risk assessment for paediatric pressure ulcer: a meta-analysis. Int J Nurs Stud 2018;5(4):419-26.

19. Mehta NM, Skillman HE, Irving SY, et al. Guidelines for the provision and assessment of nutrition support therapy in the pediatric critically ill patient: Society of Critical Care Medicine and American Society for Parenteral and Enteral Nutrition. J Parenter Enteral Nutr 2017;41(5):706-742.

20. Secker DJ, Jeejeebhoy KN. Subjective global nutritional assessment for children. Am J Clin Nutr 2007;85(4):1083-9.

21. Minocha P, Sitaraman S, Choudhary A, Yadav R. Subjective global nutritional assessment: a reliable screening tool for nutritional assessment in cerebral palsy children. Indian J Pediatr 2018;85(1):15-19.

22. White M, Lawson K, Ramsey R, Dennis N, Hutchinson Z, Soh XY, Matsuyama M, Doolan A, Todd A, Elliott A, Bell K, Littlewood R. Simple nutrition screening tool for pediatric inpatients. J Parenter Enteral Nutr 2016;40(3):392-398.

23. McCarthy $H$, Dixon $M$, Crabtree I, Eaton-Evans M, McNulty $\mathrm{H}$. The development and evaluation of the screening tool for assessment of malnutrition in paediatrics (STAMP) for use by healthcare staff. J Hum Nutr Diet 2012;25:311-318.

24. Wong S, Graham A, Hirani SP, Grimble G, Forbes A. Validation of the screening tool for the assessment of malnutrition in paediatrics (STAMP) in patients with spinal cord injuries (SCls). Spinal Cord 2013;51(5):424-9.

25. Lestari NE, Nurhaeni N, Wanda D. The pediatric Yorkhill malnutrition score is a reliable malnutrition screening tool. Compr Child Adolesc Nurs 2017;40(sup1):62-68.

26. Huysentruyt K, Alliet P, Muyshont L, Rossignol R, Devreker T, Bontems P, Dejonckheere J, Vandenplas Y, De Schepper J. The STRONG(kids) nutritional screening tool in hospitalized children: a validation study. Nutrition 2013;29(11-12):1356-61.

27. Hulst JM, Zwart H, Hop WC, Joosten KF. Dutch national survey to test the STRONGkids nutritional risk screening tool in hospitalized children. Clin Nutr 2010;29(1):106-11.

28. Black J, Alves P, Brindle CT, Dealey C, Santamaria N, Call $\mathrm{E}$, Clark M. Use of wound dressings to enhance prevention of pressure ulcers caused by medical devices. Int Wound $\mathrm{J}$ 2015;12:322-327.

29. Gorecki C, Closs SJ, Nixon J, Briggs M. Patient-reported pressure ulcer pain: a mixed-methods systematic review. J Pain Symptom Manage 2011;42(3):443-459.

30. Fox C. Living with a pressure ulcer: a descriptive study of patients' experiences. Br J Community Nurs 2002;7(6 Supp):10.

31. Spilsbury K, Nelson A, Cullum N, Iglesias C, Nixon J, Mason S. Pressure ulcers and their treatment and effects on quality of life: hospital inpatient perspectives. J Adv Nurs 2007;57(5):494-504.

32. Merkel SI, Voepel-Lewis T, Shayevitz JR, Malviya S. The FLACC: a behavioral scale for scoring postoperative pain in young children. Pediatr Nurs 1997;23(3):293-297.

33. Krechel SW, Bildner J. CRIES: a new neonatal postoperative pain measurement score. Initial testing of validity and reliability. Paediatr Anaesth 1995;5(1):53-61.

34. Bildner J, CRIES instrument assessment tool of pain in neonates. Missouri: City of Hope Pain/Palliative Care Resource Center; 1997.

35. Valizadeh L, Avazeh M, Bagher Hosseini M, Asghari Jafarabad M. Comparison of clustered care with three and four procedures on physiological responses of preterm infants: randomized crossover clinical trial. J Caring Sci 2014;3(1):1-10.

36. Ranade D, Collins N. Children with wounds: the importance of nutrition. Ostomy Wound Manage 2011 Oct;14-21. 